\title{
Esplendor y ruina de un paradigma. Lo relacio- nal: París-Madrid, Madrid-León
}

Juan ALBARRÁN DiEGO

Universidad de Salamanca

\begin{abstract}
RESUMEN. El objetivo de este artículo es analizar el nacimiento de la estética relacional como propuesta teórica y paradigma institucional a partir de los escritos y programas expositivos desarrollados por Nicolas Bourriaud desde finales de los años noventa, revisando al mismo tiempo las críticas recibidas por dicho paradigma en el contexto de una problemática articulación de lo estético, lo artístico y lo político. Acto seguido, estudiaremos hasta qué punto y desde qué presupuestos se produce un trasvase de ciertos aspectos de la estética relacional al ámbito institucional español y castellanoleonés, centrándonos en el caso concreto del MUSAC y constatando a su vez la existencia de una tradición relacional española.

Palabras clave: Arte contemporáneo, estética relacional, estudios curatoriales, políticas culturales.
\end{abstract}

ABSTRACT. The aim of this article is to analyze the birth of the relational aesthetics as a theoretical discourse and institutional paradigm in the writings and exhibition programs developed by Nicolas Bourriaud during the nineties, taking into account the critiques to this paradigm in the context of a problematic dialogue between art, aesthetic, and politics. We will study how certain aspects of the relational aesthetics were transfered to the Spanish (and Castellanoleonés) institutional context, focusing the MUSAC case and pointing the existence of a relational Spanish tradition.

Key words: Contemporary art, cultural policies, curatorial studies, relational aesthetics.

\section{LO RELACIONAL: GÉNESIS DE UN PA- RADIGMA}

La esencia de la práctica artística residiría en la invención de relaciones entre sujetos ${ }^{1}$.

Nicolas Bourriaud

En 1998 Nicolas Bourriaud publica Estética relacional, uno de los trabajos teóricos más influyentes, difundidos y discuti-

\footnotetext{
${ }^{1}$ N. BOURRIAUD, Estética relacional, Buenos Aires, 2006, p. 23.
}

dos de la última década. La primera frase del prólogo resulta extremadamente reveladora con respecto a cuáles son los objetivos del texto y del programa teóricocuratorial de su autor: “ ¿De dónde provienen los malentendidos que rodean el arte de los años noventa sino de una ausencia de discurso teórico? La mayor parte de los críticos y filósofos se niegan a pensar las prácticas contemporáneas en su totalidad, que permanecen entonces ilegibles, ya que no se puede percibir su originalidad y su pertinencia si se las analiza a partir de pro- 
blemas ya planteados o resueltos por las generaciones precedentes" ${ }^{2}$. Es decir, Bourriaud plantea la necesidad de un discurso teórico que ayude a pensar el arte actual con el fin de remediar malentendidos interpretativos y romper con el hermetismo que impide percibir su "pertinencia y originalidad". De algún modo, Bourriaud, moviéndose entre lo descriptivo y lo prescriptivo, se dispone a articular ese nuevo discurso que evite equívocos con respecto al verdadero sentido de las prácticas de los noventa.

Partiendo del análisis superficial de un conjunto bastante heterogéneo de trabajos artísticos (muchos de ellos, de un indudable interés), se aventura a proponer una suerte de relectura del proyecto moderno (obviando las enconadas discusiones filosóficas sobre el particular) a partir de la cual comprender la prácticas artísticas actuales: "No es la modernidad la que murió, sino su versión idealista y teleológica"3. El arte de hoy debe "aprender a habitar mejor el mundo, en lugar de querer construirlo según una idea preconcebida de la evolución histórica. En otras palabras, las obras ya no tienen como meta formar realidades imaginarias o utópicas, sino construir modos de existencia o modelos de acción dentro de lo real ya existente, cualquiera que fuera la escala elegida por el artista" ${ }^{4}$. Como el mismo texto de Bourriaud, "la modernidad se prolonga hoy en la práctica del bricolaje y del reciclaje de lo cultural, en la invención de lo cotidiano y en la organización del tiempo, que no son menos dignos de aten-

\section{-}

2 Ibíd., p. 5.

${ }^{3}$ Ibíd., p. 11. Posteriormente Bourriaud ha retomado estas reflexiones en torno a la actualización del proyecto moderno en N. BOURRIAUD, Formas de vida. El arte moderno y la invención de sí, Murcia, 2009; N. BOURRIAUD, Radicant. Pour une esthétique de la globalisation, París, 2009; N. BOURRIAUd (ed.), Altermodern. Tate Triennial, Londres, 2009.

${ }^{4}$ N. BOURRIAUD, Estética relacional, Op. cit., p. 12. ción y estudio que las utopías mesiánicas o las novedades formales que la caracterizaban ayer" ${ }^{\prime \prime}$.

A grandes rasgos, Bourriaud considera que las prácticas artísticas de esa década se caracterizan por la voluntad de generar espacios que posibiliten el establecimiento de lazos sociales y relaciones humanas. La obra se convertiría en un lugar de encuentro, de experiencia, de intercambio, una especie de oasis re-humanizado ajeno a las dinámicas socio-económicas alienantes que rigen las vidas de los individuos en las sociedades tardocapitalistas. De este modo, mediante el fortalecimiento de los lazos sociales, las prácticas artísticas se convertirían en armas de resistencia ante la espectacularización de la cultura, ante la cultura del espectáculo ${ }^{6}$.

El autor es consciente, y así lo explicita, de que gran parte de su discurso es aplicable a toda la historia del arte. Es decir, que toda obra de arte es, en varios sentidos, relacional. Sin embargo, argumenta, "más allá del carácter relacional intrínseco de la obra de arte, las figuras de referencia de la esfera de las relaciones humanas se han convertido desde entonces [los años noventa] en formas artísticas plenas: así, los meetings, las citas, las manifestaciones, los diferentes tipos de colaboración entre dos personas, los juegos, las fiestas, los lugares, en fin, el conjunto de los modos de encontrarse $\mathrm{y}$ crear relaciones representa hoy objetos

\footnotetext{
5 Ibíd.

${ }^{6}$ Ibíd., pp. 35 y 53. "Hoy el acento está puesto en las relaciones externas, en el marco de una cultura ecléctica donde la obra de arte resiste a la aplanadora de la sociedad del espectáculo". "Las obras producen espacios-tiempo relacionales, experiencias interhumanas que tratan de liberarse de las obligaciones de la ideología de la comunicación de masas, de los espacios en los que se elaboran, generan, en cierta medida, esquemas sociales alternativos, modelos críticos de las construcciones de las relaciones amistosas".
} 
estéticos susceptibles de ser estudiados como tales"7. Así pues, esa estética relacional que caracterizaría al arte actual, que serviría para pensar (o construir) prácticas que planteen un diálogo con el presente en el que nacen, trataría de explorar y potenciar las relaciones sociales a través de una serie de estrategias y modos de hacer extraídos de la esfera de lo social que parece pertinente trasladar al territorio del arte (al museo, a la galería): citas, encuentros amistosos, conciertos, inauguraciones, audiciones, tarjetas de invitación, comidas, fiestas, contratos, etc.

Estos y otros muchos eventos quedarán perfectamente integrados (de hecho, serán fundamentales) en la programación del Palais de Tokyo, que Bourriaud dirige, junto con Jerôme Sans, entre 1999 y 2006. En esta institución Bourriaud encuentra el lugar idóneo en el que llevar a la práctica las propuestas teóricas de su estética relacional. Desde sus críticas como corresponsal de Flash Art entre 1987 y 1995, su labor editorial en la revista Documents sur l'art, que funda en 1992, comisariados como los del Pabellón Francés de la Bienal de Venecia de 1991, el Aperto de esa misma bienal en 1993 o la colectiva Traffic ${ }^{8}$ (CAPC, Bur-

\footnotetext{
${ }^{7}$ Ibíd, pp. 31-32.
}

8 N. BOURRIAUD, «Traffic: Espaces-temps de l'échange», en Traffic, Burdeos, 1996. En esta muestra participaron Vanessa Beecroft, Henry Bond, Angela Bulloch, Jes Brinch y Henrich Plenge Jakobsen, Maurizio Cattelan, Andrea Clavadetscher y Eric Schumacher, Honoré D'O, Liam Gillick, Dominique González Forester, Douglas Gordon, Jens Haaning, Lothar Hempel, Christine Hill, Noritoshi Hirakawa, Carsten Höller, Pierre Huyghe, Peter Land, Miltos Manetas, Gabriel Orozco, Jorge Pardo, Philippe Parreno, Jason Rhoades, Christopher Sperandio y Simon Grennan, Rirkrit Tiravanija, Xavier Veilhan, Gillian Wearing, Kenji Yanobe. Para Bourriaud, los trabajos de todos ellos "opèrent au sein d'un même horizon practique et théorique: la sphère des rapports inter-humains. (...) Tous oeuvrent donc au sein de ce que l'on pourrait nommer la sphère relationnelle". deos, 1996), en cuyo catálogo comienza a teorizar sobre la estética relacional, Bourriaud llevaba más de una década cimentando un modelo que se consolidará a nivel internacional en las salas del parisino Palais de Tokyo.

La creación de este centro de arte (concebido en 1999, inaugurado en 2002 y financiado en un $70 \%$ por el Ministerio de Cultura francés) se produce en un contexto de crisis en el seno de las instituciones dedicadas al arte contemporáneo en Francia. Varias voces señalaban entonces (a finales de los noventa) la falta de espacios dedicados al arte actual en la capital francesa así como la incapacidad de los ya existentes para hacer que el gran público se interesase por la creación contemporánea ${ }^{9}$ Al mismo tiempo, se producía un debate acerca de la escasa proyección del arte francés en el exterior, tanto a nivel crítico-mediático como en lo referente a su cuota de merca$\mathrm{do}^{10}$. En esta complicada coyuntura, la dirección del nuevo centro de creación contemporánea recayó en los críticos y comisarios independientes Nicolas Bourriaud y Jérôme Sans, que van a tener unos objetivos bastante bien definidos en el horizonte inmediato: dar visibilidad en foros internacionales al arte emergente producido en Francia, acercar la creación actual al gran público y acallar las voces críticas que acusaban a las administraciones francesas de no apoyar las manifestaciones artísticas más recientes. Todo ello, claro está, en una ciudad como París, que en las últimas dé-

${ }^{9}$ C. FRANCBLIN, «Paris, malaise dans l'institution», Art press no250, 1999.

${ }^{10} \mathrm{P}$. ARDENNE, «Rapport Quemin, analyse d'une désaffection», Art press no 278, 2002. Por encargo del Ministerio francés de Asuntos Exteriores, el sociólogo Alain Quemin redactó en 2001 un informe titulado $E l$ rôle des pays prescripteurs sur le marché et dans le monde de l'art contemporaine en el que exponía la progresiva pérdida de protagonismo del arte contemporáneo francés en el sistema internacional del arte.
} 
cadas había aportado poco a los discursos artísticos contemporáneos (nada si lo comparamos con la producción crítica norteamericana o el éxito mediático de los Young British Artists) y que pretende consolidarse como una gran capital cultural y turística a nivel mundial.

La estética relacional, convenientemente matizada y reforzada por su autor en Formas de vida y Post-producción ${ }^{11}$, contribuirá a legitimar y fundamentar desde un punto de vista teórico los objetivos estratégicos de la nueva institución. El hecho de que los espacios artísticos sean lugares habitables (y no sólo espacios destinados a la contemplación de obras), unido a una cierta "desintelectualización" del discurso artístico y al papel protagónico de inauguraciones, fiestas y eventos paralelos aseguran un elevado número de visitas. A esa instauración de "intersticios relacionales" contribuiría la estética industrial, inacabada, casi ciber-punk (alejada del habitual cubo blanco) de los espacios arquitectónicos ${ }^{12}$, así como el "ambiente juvenil" y la importancia concedida a la tienda, la librería y, muy especialmente, al restaurante, dirigido por el conocido chef Bernard Leprince. Estas particularidades y el considerable interés que ya en 2002 despertaba el proyecto relacional han conseguido atraer una enorme

-

${ }^{11}$ N. BOURRIAUD, Formas de vida, Op. cit.; N. BOURRIAUD, Post producción. La cultura como escenario: modos en que el arte reprograma el mundo contemporáneo, Buenos Aires, Adriana Hidalgo, 2004.

12 Los espacios expositivos del Palais de Tokyo son el resultado de la intervención diseñada por los arquitectos Anne Lacaton et Jean-Philippe Vassal sobre el Pabellón de Japón de la Exposición Universal de 1937. D. ARNAUDET, "Anne Lacaton et Jean-Philippe Vassal, des situations d'existence», Art press no 275, 2002, p. 52: "Nous avons ainsi abordé le projet du Palais de Tokyo comme un espace à habiter par des artistes, par le public, avec l'idée de faire des espaces les plus ouverts, les plus évidents, les plus réceptifs posibles, et cela dans un grande proximité avec les directeurs Nicolas Bourriaud et Jérôme Sans pour coller au plus près du projet artistique". atención mediática sobre unas exposiciones de montajes casi siempre espectaculares (lo cual predispone a una recepción emocional de las obras), enmarcadas en una programación que alterna individuales de artistas emergentes y colectivas "de tesis" (GNS, 2003; Hardcore, 2003; Playlist, 2004; Translation, 2005; Notre histoire, 2006).

Todo ello convierte la estética relacional en un último paradigma ${ }^{13}$. El último modelo teórico-institucional aparecido en el contexto artístico internacional capaz de poner sobre la mesa una oferta nada desdeñable, una especie de tres por uno $(3 \times 1)$ : un conjunto de artistas que ven cómo sus carreras se consolidan gracias, en parte, a este paradigma relacional y cuya producción queda (por más que les pese) connotada dentro del mismo (Parreno, GonzálezForester, Huyghe); un discurso teórico que, pese a las fisuras (a continuación revisaremos algunas de las críticas recibidas), logra tener una enorme resonancia (Estética relacional continúa reeditándose y ha sido traducido a quince idiomas); y un modelo institucional, un centro de arte emergente, joven, flexible, capaz de adaptarse a las fluctuaciones discursivas y mercantiles del arte actual, y que, además, ha cumplido los objetivos estratégicos marcados desde las

${ }^{13}$ Como modelo institucional radicalmente opuesto en sus objetivos y gestación al Palais de Tokyo encontramos el Plateau, pequeño espacio dedicado al arte contemporáneo situado en un barrio popular de la capital. Inaugurado también en 2002, el proyecto nace en 1995 cuando Eric Corne crea la asociación vecinal Vivre aux Buttes-Chaumont con el fin de frenar los agresivos planes de reurbanización de la zona. Considerando que el proyecto de la sociedad constructora Stim-Batir no tenían en cuenta las necesidades del barrio, cientos de vecinos mantuvieron una batalla legal con los responsables de la administración y de la sociedad promotora que, finalmente, accedió a modificar el proyecto incluyendo la construcción de un centro de arte. S. WRIGHT, «Art contemporain et démocratie de voisinage», en http://www.cairn.info/ article.php?ID_ ARTICLE $=$ MOUV_017_0078\& AJOUTBIBLIO=MOUV_017_0078 
altas instancias políticas que concibieron el proyecto (promoción del arte francés ${ }^{14}$, elevado número de visitantes, visibilidad mediática, etc.). Un modelo reconocible, atractivo, exportable y recubierto por una halo de falsa novedad promocional.

\section{CRÍTICAS A LO RELACIONAL: UNA POSTMODERNIDAD NOSTÁLGICA}

La mayor parte de críticas que ha recibido el proyecto de Bourriaud están relacionadas con la imbricación de un discurso estético (que se pretende también político ${ }^{15}$ ) y un programa institucional. Ya en Estética relacional, Bourriaud trataba de resguardarse de los ataques que su modelo iba a recibir:

"Las prácticas artísticas relacionales son objeto de crítica reiterada porque se limitan al espacio de las galerías y de los centros culturales, contradiciendo ese deseo de lo social que es la base de su sentido. Se le reprocha que niegan los conflictos sociales, las diferencias, la imposibilidad de comunicar en un espacio social alienado, en beneficio de una modelización ilusoria y elitista de las formas de lo social, porque se limita al medio del arte. (...) La principal queja sobre el arte relacional es que representaría una forma

-

${ }^{14}$ Con respecto a la promoción de una joven generación de artistas franceses, resulta interesante la polémica que envolvió la exposición Notre histoire (Palais de Tokyo, 2006). C. STAEBLER, «Nicolas Bourriaud et Jérôme Sans, directeurs du Palais de Tokyo, site de création contemporaine, interviewés par Claire Staebler», en Notre Histoire. Une scène artistique française émergente, París, 2006; J. LAVRADOR; E. LEQUEUX; A. PICQ, «Le Palais de Tokyo fait une scène à la nouvelle génération», Beaux Arts Magazine no 259, 2006; $\mathrm{H}$. GAUVILLE; E. LEBOVICI, «Notre histoire à dormir debout», Libération, 24 de enero de 2006; N. BOURRIAUD, «Guichet Départ», Beaux Arts Magazine no 264, 2006.

${ }^{15}$ Bourriaud llega a hablar de la creación artística como un "instrumento de emancipación y herramienta política que busca la liberación de las subjetividades". N. BOURRIAUD, Estética relacional, Op. cit., p. 96. suavizada de la crítica social. / Lo que estas críticas olvidan es que el contenido de estas propuestas artísticas debe ser juzgado formalmente: en relación con la historia del arte, tomando en cuenta el valor político de las formas, lo que llamo el criterio de coexistencia, a saber: la transposición en la experiencia de vida de los espacios construidos o representados por el artista, la proyección de lo simbólico en lo real"16.

Resulta contradictorio que Bourriaud llegue a defender un juicio basado en el lugar que lo relacional ocupa en la historia del arte, cuando él mismo, en otros puntos del texto, parece argumentar casi lo contrario: que el arte relacional sólo tiene sentido como proveedor de espacios para la experiencia en el presente y que poco importa, por tanto, que esos mismo objetivos fuesen la razón de ser de otras prácticas (situacionistas o conceptuales), pues la necesidad actual de esos espacios capaces de restituir el vínculo social legitimaría lo relacional ${ }^{17}$. De este modo, se alinea con los argumentos que sustentan las intervenciones artísticas más comprometidas social y políticamente (arte activista, intervenciones en el espacio público, etc.), en relación a las cuales poco importa la novedad y originalidad de sus planteamientos ya que los contextos sobre los que operan están en constante transfor-

-

${ }^{16}$ Ibid., pp. 102-103.

17 Ibíd., pp. 34 y 53. "Lo provisional de ciertas formas para las relaciones sociales es una constante histórica desde los años sesenta. La generación de los noventa retoma esta problemática, central en las décadas de 1960 y 1970, pero deja de lado la cuestión de la definición del arte. El problema ya no es desplazar los límites del arte, sino poner a prueba los límites de resistencia del arte dentro del campo social global". "En lo que se refiere a los artistas relacionales estamos en presencia de un grupo que por primera vez desde la aparición del arte conceptual, a mediados de la década de 1960, no parten en absoluto de la reinterpretación de tal o cual movimiento estético pasado; el arte relacional no es el renacimiento de un movimiento o estilo. Nace de la observación del presente y de una reflexión sobre el destino de la actividad artística". 
mación y sólo su "efectividad" puede dotarlas de sentido ${ }^{18}$.

La cuestión de la originalidad y novedad de las propuestas de Bourriaud y de las aportaciones de los trabajos relacionales no tendría demasiada importancia de no ser por la ambivalencia con que el mismo autor utiliza estos criterios a la hora de justificar su programa estético. Bourriaud cita a artistas del ámbito conceptual (Dan Graham, Matta-Clark, On Kawara, Robert Barry) como antecedentes y fuentes de legitimidad, pero asegura que los "relacionales" van más allá en sus planteamientos (recuperar el vínculo social) sin importarles los problemas de tipo lingüístico (intraartístico). Otros artistas y grupos que Bourriaud por supuesto conoce ${ }^{19}$ (la Internacional Situacionista, Fluxus, los primeros hackers, etc.) desarrollaron algunos puntos contenidos en el programa relacional, llevando hasta sus últimas consecuencias el potencial político del mismo y asumiendo sus posibles contradicciones. Eso sí, siempre al margen de los intereses de las instituciones y renunciando a participar en proyectos estéticos orquestados "desde arriba". En cualquier caso, si Bourriaud no contempla la novedad como uno de los motores de su programa, si lo que interesa de las prácticas relacionales es su capacidad para generar espacios de sociabilidad al margen de que sus modelos formales sean o no innovadores, ¿cómo interpretar entonces la búsqueda constante de nuevos valores artísticos?, ¿cómo explicar esa obsesión por la juventud, convertida en valor estético su-

\footnotetext{
${ }^{18}$ L. LIPPARD, «Mirando alrededor: dónde estamos y dónde podríamos estar», en Modos de hacer. Arte crítico, esfera pública y acción directa, Salamanca, 2002, p. 66.

${ }^{19}$ D. BAQUÉ, Pour un nouvel art politique. De l'art contemporain au documentaire, París, 2006, p. 150; P. ARDENNE, Un arte contextual, Murcia, 2005, pp. 133137.
}

premo, sino es desde la imperiosa necesidad de poner en circulación nuevos productos artísticos en un sistema del arte ya saturado?

Por otra parte, Bourriaud pretende recuperar el proyecto moderno desprendiéndose de dogmatismos ideológicos y lecturas teleológicas al tiempo que da por periclitada la postmodernidad (sin llegar nunca a explicar qué significa para él este concepto). Y sin embargo, el gusto por la cita, por el reciclaje, por el bricolaje cultural, por la apropiación y recontextualización de referentes artísticos, el afán por revestir de una nueva artisticidad elementos que están más allá del espacio sagrado del arte, nos hacen pensar, como bien ha señalado Domingo Hernández Sánchez ${ }^{20}$, en una "nostalgia de postmodernidad". La que, bajo la presión de las industrias del ocio y los aparatos de promoción cultural, trata de revalorizar elementos ajenos a lo artístico (reuniones, fiestas, cenas, etc.), que son trasladados desde los espacios profanos al terreno del arte, creando así valor cultural a través de una novedad que resulta, en el fondo, imposible ${ }^{21}$. Bourriaud es consciente de que el valor de lo relacional está en el uso "artístico" de aquello que en principio no lo es (aunque sí lo ha sido). Ya no hay nada nuevo (algo muy postmoderno) en su programa, salvo el hecho de haber sido articulado desde la institución.

Por tanto, como estamos viendo, el espacio en el que opera un trabajo relacional es siempre, de manera exclusiva, el del museo o la galería. Activando una especie de proceso domesticador del malestar social, Bourriaud consigue que la producción

\footnotetext{
${ }^{20}$ D. HERNÁNDEZ SÁNCHEZ, «Copias, postproducciones y otras estéticas del guardar como», Contrastes. Suplemento $\mathrm{n}^{\mathrm{o}}$ 13, 2008.

${ }^{21}$ B. GROYs, Sobre lo nuevo. Ensayo de una economía cultural, Valencia, 2005, pp. 75-97.
} 
de espacios de sociabilidad desde lo estético-artístico quede reducida a unos ámbitos institucionales en los que resulta difícil saber dónde termina la experimentación formal y dónde empieza el mero esparcimiento, confundiéndose de manera preocupante los conceptos de laboratorio (investigación, estudio) y parque temático (ocio, diversión). Como ha señalado Anthony Downey en su crítica a la estética relacional22, el espacio público ya no es el lugar donde se generan esas relaciones y experiencias comunitarias que parecen perseguir las prácticas relacionales, sino el ámbito controlado y saneado del museo. Lo relacional participaría así de un perverso proceso de privatización e institucionalización de la esfera pública, terreno en el que debería ponerse en escena el disenso como base sobre la que construir una experiencia comunitaria realmente democrática.

Dentro del programa relacional, éste es uno de los puntos más espinosos. Bourriaud afirma: "Las obras de arte que me parecen dignas de interés hoy son aquéllas que funcionan como intersticios, como espacios-tiempo regidos por una economía que está más allá de las reglas concernientes a la gestión de los públicos. Lo que nos llama la atención, en el trabajo de esta generación de artistas es, en primer lugar, la preocupación democrática que lo habita"23. Habría que preguntarse, como han hecho Claire Bishop y Julia Svetlichnaja ${ }^{24}$, a qué

-

22 A. DOWNEY, «Towards a Politics of (Relational) Aesthetics», Third Text 21:3, 2007.

23 N. BOURRIAUD, Estética relacional, Op. cit., p. 69.

${ }^{24} \mathrm{C}$. BISHOP, «Antagonism and Relational Aesthetics», October nº 110, 2004; J. SVETLICHNAJA, «Relational Paradise as a Delusional Democracy. A Critical Response to a Temporary Contemporary Relational Aesthetics», conferencia presentada en Art and Politics, 2005, Universidad de St. Andrews, St. Andrews, Scotland. Véase también L. GILLICK, «Contingent Factores: A Response to Claire Bishop's Antagonism and Relational Aesthetics», October no ${ }^{-115,} 2006$. tipo de experiencia o preocupación democrática se refiere el crítico francés. ¿Qué tipo de relaciones humanas generan los trabajos relacionales?, ¿tienen continuidad más allá del marco de excepcionalidad relacional que constituye el espacio expositivo?, ¿hasta qué punto la participación (opuesta a la mera contemplación ${ }^{25}$ ) de los visitantes asegura el establecimiento de relaciones sociales?, ¿qué consistencia tienen esas relaciones mediadas por instituciones con un claro objetivo mediático-propagandístico?,

${ }^{25}$ Rancière (J. RANCIÈRE, Le spectateur émancipé, París, 2008) y Bourriaud (N. BOURRIAUD, «Precarious Constructions. Answer to Jacques Rancière on Art and Politics», http://www.skor.nl/article-4416-nl.html? Lang $=e n)$ protagonizaron un intercambio dialéctico a propósito de la contraposición contemplación / participación. Uno de los ejes del pensamiento estético de Rancière pasa por despolarizar la oposición entre una participación supuestamente emancipadora y una contemplación alienante. La teoría de Bourriaud se basa en la mitificación de la participación como generadora de relaciones. Algo que Rancière, por supuesto, pone en duda. Bourriaud es realmente hábil en su respuesta, pues algunos pasajes del artículo en que Rancière despliega sus críticas hacia "el arte político" parecen coincidir en varios puntos con los postulados de la estética relacional ("L'efficacité de l'art ne consiste pas à transmettre des messages, donner des modèles ou des contre-modèles de comportement ou apprendre à déchiffrer les representations. Elle consiste d'abord en dispositions des corps, en découpage d'espaces et de temps singuliers qui définissent des manières d'être ensembles o séparés, en face de ou au milieu de, dedans ou dehors, proches ou distants"). Sin embargo, Rancière (y es algo a lo que Bourriaud no da respuesta) señala lo problemático de una equivalencia entre los espacios públicos y museales como ámbitos de producción de relaciones sociales, desvelando al tiempo el hecho paradójico de que esas relaciones que pretenden escapar de la mera contemplación reverencial de los trabajos artísticos se produzcan en un espacio diseñados para tal fin ("L'intérieur de l'espace muséal et l'extérieur de la vie social apparaissent alors comme deux lieux équivalents de production de rapports. Mais cette banalisation montre aussitôt son envers: la dispersion des oeuvres de l'art dans la multiplicité des rapports sociaux ne vaut pas qu'à être vue, soit que l'ordinaire de la relation où il n'y a rien à voir soit exemplairemente logé dans l'espace normalemente destiné a l'exhibition des oeuvres; soit qu'à l'inverse la production de liens sociaux dans l'espace public se voit pourvue d'une forme artistique spectaculaire"). 
¿tiene cabida el disenso (base de toda experiencia democrática) en el marco de esas relaciones? Parece que el tipo de experiencia democrática que pueden proporcionar las prácticas relacionales estaría bastante próximo a la democracia formal de nuestras sociedades: la democracia del número de votantes, o de visitantes en este caso (el Palais de Tokyo recibió 900.000 visitas entre 2002 y 2006), de la cantidad por encima de la calidad, de una comunidad débil construida desde arriba (bajo el auspicio del comisario como nueva estrella mediática del sistema), una experiencia democrática controlada por la institución (no democrática) en la que no tiene cabida el antagonismo, ni la alteridad, ni tan siquiera la crítica institucional. Relaciones democratizadoras dirigidas a un grupo social (el público del museo) homogéneo, armonioso, predispuesto al ocio y carente de conflictos que puedan ser enunciados en ese nuevo espacio de sociabilidad ${ }^{26}$. El arte relacional podría ser considerado, incluso, como una especie de sustitutivo de lo político, como un espacio compensatorio en el que las tensiones sociales se relajan evitando que los problemas sean enunciados en otros ámbitos públicos en los que sí podrían adquirir "relevancia" política 27.

En varios sentidos, lo relacional termina por reafirmar las dinámicas espectacularizantes a las que, de algún modo, pa-

${ }^{26}$ S. BISET, «L'art, espace potentiel de sociabilité. Sur les agents relationnels de l'art à l'heure de l'asepsie autoproclamée», en Les formes contemporaines de l'art engagé: de l'art contextuel aux nouvelles practiques documentaires, Bruselas, 2007, pp. 70-71.

${ }^{27}$ H. FOSTER, «(Dis)engaged art», en Right About Now. Art and Theory since the 1990s, Amsterdam, 2006, p. 77: "Even an art audience cannot be taken for granted but must be conjured up every time, wich might be why contemporary exhibitions often feel like remedial work in socialization: come look, talk and learn with me. If participation appears threatened in others spheres, its privileging in art might be compensatory". rece querer resistirse en el ámbito de la producción y difusión de la cultura, desmantelando, al mismo tiempo, las posibilidades del arte como generador de dinámicas emancipadoras (más o menos utópicas) no mediatizadas por la institución. Teniendo en cuenta el papel desempeñado por el programa relacional en el marco de las políticas culturales expuestas así como los problemas discursivos que acabo de glosar, varios autores ${ }^{28}$ han señalado cómo la estética relacional reproduce (más que cuestiona o replantea) la banalización de la cultura y la mercantilización de las relaciones humanas impuesta por el nuevo capitalismo.

UNA TRADICIÓN RELACIONAL: BOUTIQUES, DISCOTECAS Y OTRAS MOVIDAS

Convertir un museo en una discoteca o una sala de espera de aeropuerto en un puticlub no es arte sino entretenimiento ${ }^{29}$. Kevin Power

Después de lo expuesto hasta aquí, me atrevería a aventurar que la problemática que envuelve a lo relacional e, incluso, que lo relacional mismo es algo típicamente español. $\mathrm{O}$, al menos, que el devenir de nuestro arte contemporáneo, teniendo en cuenta los procesos de crecimiento de la institución, el desarrollo de las políticas culturales y las dinámicas artísticas de la España democrática, iba a desembocar, en algún momento y de manera irremediable, en lo relacional. Podríamos afirmar que, a grandes rasgos, las políticas artísticas desplegadas durante los años ochenta fueron centralistas, verticales, megalómanas, poco democráticas y nada democratizadoras,

${ }^{28}$ C. BISHOP, «Antagonism and Relational Aesthetics», Art. cit., p. 58; A. DownEY, «Towards a Politics of (Relational) Aesthetics», Art. cit., p. 271.

${ }^{29}$ K. POWER, «Tras la euforia: los 90», en Impasse 5. La década equívoca: el trasfondo del arte contemporáneo español en los 90, Lleida, 2005, p. 207. 
desestructuradas, carentes de cualquier tipo de planificación y tendentes a convertir el arte en un espectáculo de masas $^{30}$. Como consecuencia directa del proceso transicional, la cultura se convierte en un entretenimiento mediático, "un invento del gobierno" que privilegia su lado más festivo y carnavalesco $^{31}$.

La movida (fenómeno relacional donde los haya) es la cara más visible de ese proceso de banalización, desactivación e instrumentalización de la cultura. Asistir a fiestas o conciertos, salir por la noche, ir de compras, travestirse, someterse a una sesión fotográfica en casa de un amigo, beber, drogarse o simplemente relacionarse hasta altas horas de la madrugada se convierten en manifestaciones privilegiadas de la esplendorosa cultura democrática, joven, libre, (post)moderna y horizontal. Esta visión hedonista y desenfadada de la cultura encontrará una particular prolongación en las inauguraciones, eventos en los que la nueva (o no tan nueva) clase política descubre un magnífico escaparate en el que hacerse la foto. Salvando las distancias, tenemos muchos de los elementos de lo relacional en un panorama artístico que, sin embargo, estaba dominado por corrientes pictóricas próximas a la transvanguardia y el neoexpresionismo. Es decir, un tipo de

-

${ }^{30} \mathrm{~J}$. L. BREA, «El desarrollo de la institución arte en la España de la democracia», Revista de Occidente $\mathrm{n}^{\mathrm{o}}$ 273, 2004; J. L. MARZO; T. BADÍA, «Las políticas culturales en el Estado español (1985-2005)», en http:// www.soymenos.net/

${ }^{31}$ R. SÁNCHEZ FERLOSIO, «La cultura, ese invento del Gobierno», El País, 22 de noviembre de 1984: "El prestigio de la fiesta y de lo festivo parece haberse vuelto hoy tan intocable, tan tabú, como el prestigio del pueblo y lo popular. No se diría sino que una férrea ley del silencio prohíbe tratar de desvelar el lado negro, oscurantista, de las fiestas, lo que hay en ellas de represivo pacto inmemorial entre la desesperación y el conformismo, y que, a mi entender, podría dar razón del hecho de que en el síndrome festivo aparezca justamente la compulsión de la destrucción de bienes o el simple despilfarro". prácticas que privilegiaban la contemplación y el placer retiniano por encima de la participación del espectador y que, gracias a su éxito crítico internacional y a la consiguiente rentabilidad mediática (política, electoral), contribuyeron al olvido sistemático de todas aquellas manifestaciones artísticas de cariz conceptual que se habían desarrollado durante los últimos años de la dictadura desde posiciones políticas antifranquistas. A finales de los ochenta, puede localizarse un agotamiento de la anterior veta pictórica y un repunte de (o un aumento de la presencia expositiva y atención institucional sobre) la escultura y la instalación ${ }^{32}$. Al mismo tiempo, en esos mismos años, comienza a hablarse de una tímida ola neoconceptual encarnada por una generación de artistas (la de los primeros noventa) que, en lo formal, abandona la práctica de la pintura (hegemónica hasta entonces) $\mathrm{y}$, en lo conceptual, da continuidad al solipsismo de la década anterior mediante trabajos subjetivos centrados en la identidad, el cuerpo y la sociedad de consumo. En esos momentos, el rumbo de las políticas culturales no había cambiado demasiado (salvo por la crisis económica que sigue a los fastos del 92): continúan abriéndose centros de arte y museos a un ritmo cada vez mayor sin conseguir crear un tejido artístico tupido y duradero, el arte y la cultura siguen (y seguirán) siendo un elemento más dentro de las campañas de imagen desplegadas por los partidos en el poder $\mathrm{y}$, por más que se produzca una recuperación de trabajos de inspiración conceptual, el proceso de desintelectualización y desactivación política de lo artístico que se había puesto en marcha en la transición continúa operativo hasta la actualidad.

\footnotetext{
32 S. MARCHÁN FIZ, «Las artes en transición», en Arte contemporáneo español. Museo Patio Herreriano, Valladolid, 2002, p. 245; M. SÁNCHEZ ARGILÉS, La instalación en España, 1970-2000, Madrid, 2009, pp. 106107.
} 
En ese contexto, durante los años noventa se generalizará lo que Mónica Sánchez Argilés denomina "instalación contextual" ${ }^{\prime 33}$ (que bien podríamos entender como instalación relacional pese a las obvias diferencias entre lo "contextual" de Ardenne y lo relacional de Bourriaud ${ }^{34}$ ). Sin duda, Ana Laura Aláez es la artista más representativa de este tipo de propuestas instalativas que tan bien se ajustan a lo postulado por Bourriaud en su Estética relacional. El trabajo de Aláez constituye un interesante caso de estudio ya que su trayectoria puede considerarse sintomática de un cierto estado de cosas en el seno de la Institución-arte así como de la evolución de una parte significativa de la producción artística española durante la década de los noventa.

She Astronauts (Sala Montcada, Fundació La Caixa, Barcelona, 1997) es una tienda de ropa fashion en la que Aláez reproduce los mismos mecanismos de alienación emocional (fetichización, seducción, placer derivado de la posesión) que despiertan nuestros deseos de consumo. La instalación plantea la estetización y la pérdida del valor de uso de unos espacios que, fuera de los muros de las salas de exposiciones, desempeñan un papel fundamental en el sistema de distribución de mercancías. Al mismo tiempo, la baja cultura irrumpía en el museo frustrando las expectativas que el consumidor de alta cultura lleva consigo al entrar en un espacio destinado al arte, supuestamente ajeno a las perversos intereses de las industrias del ocio y el espectáculo. En este lugar habitable, Aláez "burlaba cualquier límite diferenciador entre arte, arquitectura, diseño de interior, galería de arte o moda. Aprovechando al máximo la

\footnotetext{
33 Ibíd., pp. 179-209.

34 Pese a que encontramos conexiones obvias entre ambos "programas", el mismo Ardenne ha sido muy crítico con las propuestas de Bourriaud. P. ARDENNE, Un arte contextual, Op. cit., pp. 133-137.
}

circunstancia de que en nuestra sociedad hiperestetizada en la que todo se parece a todo, aunque nada es realmente lo que parece" $^{35}$. La instalación se convertía, como explica Badiola, en "un espacio social de relación en donde los espectadores no eran obligados por las características de los objetos a un tipo de relación predeterminada, sino más bien incentivados a mayores $\mathrm{y}$ más complejos sistemas de intercambio"36.

Así pues, el trabajo de Ana Laura participa de dos nociones que Dominique Baqué considera paradigmáticas del nuevo régimen del arte como espectáculo: architainment (arquitectura + entretenimiento) y fun shopping ${ }^{37}$. Comprar y divertirse, pilares de la actual sociedad de consumo, se trasladan al mundo del arte: el creador diseña espacios destinados al consumo y el entretenimiento evitando que el espectador se pregunte qué se esconde detrás de esa cultura de la diversión o en qué medida resulta interesante (o si quiera pertinente) su irrupción en los espacios dedicados a la exhibición de obras de arte. No obstante, el museo, convertido en un parque temático, se presenta como una especie de dispositivo crítico que potencia las relaciones humanas en estos nuevos espacios de sociabilidad.

Encontramos otro ejemplo de esa deriva relacional en Dance \& Disco (Espacio Uno, MNCARS, Madrid, 2000), instalación que, en palabras de Rafa Doctor (comisario de la exposición), es "el club ideal que a ella [Ana Laura Aláez], y a muchos de nosotros, nos hubiera gustado disfrutar en una ciu-

\footnotetext{
-

${ }^{35}$ M. SÁNCHEZ ARGILÉS, La instalación en España, Op. cit., p. 206.

${ }^{36}$ T. BADIOLA, «Dos o tres cosas que estaría bien saber de ella», en Ana Laura Aláez. Using your Guns, León, 2008, p. 94.

${ }^{37}$ D. BAQUÉ, Pour un nouvel art politique, Op. cit., p. 79.
} 
dad tan dedicada a la fiesta como es Madrid. (...) Durante las mañanas, el bar permanecía abierto y se podía contemplar todo aquello como una instalación más. Por las tardes, sin embargo el lugar tomaba vida y la contemplación no tenía validez si no era seguida de la participación real" ${ }^{\prime 3}$. En relación con su proyecto, Ana Laura Aláez ha explicado:

"Cuando Rafa Doctor, comisario del Espacio Uno, me propuso hacer algo, pensé inmediatamente en una discoteca. (...) Se me ocurrió el diseño de un espacio funcional. Sí, sería un club pequeño, como los que me gustan a mí. Adoro los espacios que acogen al espectador, que no lo expulsan. Lugares que corresponden a la escala humana. Los locales de ocio deberían tener una fecha de caducidad. Creo que los clubs en Madrid no son estéticamente bonitos. No se corresponde su calidad musical con el contenedor. La fecha de caducidad de la disco fue de seis semanas; poco tiempo para algo que se estaba desarrollando a una velocidad feroz. Se inauguró el día 5 de febrero de 2000 a las 18,30 horas, con una sesión de música. Nos sorprendió la larga cola que desbordaba las puertas del museo. Hubo gente que esperó pacientemente su turno, hubo otros que se enfadaron por no poder entrar. Algunos nos criticaron la mala organización en la apertura del evento, pero ni Rafa ni yo contábamos con una respuesta masiva. No podíamos - a pesar del apuro - dejar de pensar que aquello suponía un pequeño éxito: ¿acaso, la gente no espera para entrar en un club? (...) El ambiente que se creó fue muy especial, yo misma me preguntaba: ¿Cómo es posible que estemos haciendo esto en el recinto -casi sagrado- de un museo? ¿Cómo nos lo podemos estar pasando tan bien cuando los vi-

\footnotetext{
38 Citado por M. SÁNCHEZ ARGILÉS, La instalación en España, Op. cit., p. 209.
}

gilantes nos están esperando casados, con cara de pocos amigos?"39

De las palabras de Aláez se desprende que el arte es siempre aburrido y los museos, sitios donde el disfrute está prohibido, por lo que parece del todo necesario introducir la cultura de club, el buen rollo juvenil y la diversión nocturna en el templo del arte. "Desartizar" el museo y "artistizar" el ocio como ejercicio de experimentación, provocación y cuestionamiento de la función de las instituciones artísticas. Teniendo en cuenta que la misma Ana Laura siempre ha mantenido que "no hay que entender el arte, hay que sentirlo", parece inevitable considerar estas instalaciones como simples celebraciones obscenas y complacientes de la cultura de masas, trabajos que condicionan una recepción irreflexiva del arte en su búsqueda de nuevos espacios de sociabilidad.

En varios sentidos, con Ana Laura Aláez, la movida (su versión más sofisticada y menos "cutre", más internacional y menos castiza) entra, por fin, en el museo, en el corazón mismo de la Institución-arte. Por supuesto, ya lo habían hecho antes productos artísticos vinculados a la movida (Pérez Villalta, Barceló, etc.), pero no su esencia misma, no las manifestaciones de una relacionalidad hispánica, juvenil, amnésica, despreocupada, desintelectualizada, festiva y puramente emocional. A menudo se habla de una institucionalización e instrumentalización de la movida, que durante los primeros ochenta pasaría de ser un "carnaval underground" a una "marca registrada" 40 . Con Ana Laura, la movida, nuestra postmodernidad nerviosa, es direc-

\footnotetext{
39 A. L. AlÁEZ, «Dance \& Disco», en Flúor, Madrid, 2003.

${ }^{40}$ P. CARMONA, «La pasión capturada. Del carnaval underground a la Movida madrileña marca registrada», en Desacuerdos 5, Barcelona, 2009.
} 
tamente producida y promocionada por el museo: no es institucionalizada, es institucional. De este modo, a finales de los noventa, lo relacional irrumpe en el panorama artístico español. El crecimiento de la institución se encuentra en el momento idóneo, un punto en el que el grado de banalización de lo artístico ha alcanzado un nivel suficientemente elevado como para que ya no haga falta mostrar ningún tipo de recato, no es necesario recubrir de un barniz cultural una manifestación lúdica: una fiesta nocturna puede entrar tal cual en (o puede generarse desde) el espacio destinado a la cultura porque fiesta y arte contemporáneo serán en adelante una misma cosa.

Con respecto a la relación entre el discurso relacional de Bourriaud y el trabajo de Aláez, no es que, como explica Badiola, Ana Laura haya captado de manera "intuitiva" 41 , participando de una especie de espíritu de época, las dinámicas que estaba describiendo y defendiendo el comisario francés. No me atrevería a insinuar una influencia de la estética relacional en el trabajo de Aláez, sino que Ana Laura (y el apoyo que recibe de comisarios como Doctor) encarna a la perfección esa tradición relacional española, la movida, que, ya globalizada, llegará a ser exportada al gran templo de lo relacional (en 2003, Aláez diseña para el Palais de Tokyo la instalación Beauty Cabinet Prototype).

Si nos centramos en la figura del responsable del proyecto que Aláez realiza para Espacio Uno, Rafael Doctor Roncero, es de sobra conocido su interés por la movida madrileña así como su admiración

${ }^{41}$ T. BADIOLA, «Dos o tres cosas que estaría bien saber de ella", Art. cit., p. 94: "Al abordar estas problemáticas, Ana Laura Aláez se hacía intuitivamente eco de todo un pensamiento que permanecía latente en aquellos momentos en torno al arte contextual y que tomó cuerpo varios años después, en el año 2000 [sic], en el texto de Nicolás Bourriaud titulado Estética Relacional". hacia artistas como Pablo Pérez Mínguez, Ouke Leele o Alaska, iconos de aquella fiebre creativa que explota en los ochenta y que parece reverdecer en algunos de sus proyectos. Doctor es una figura clave para entender la evolución del arte español durante los años noventa. Entre 1993 y 2000 se encarga de la programación de la sala Canal de Isabel II (Comunidad de Madrid), que desempeñará un papel importante en la normalización de la fotografía dentro el panorama artístico español. Doctor coordinará la programación del Espacio Uno del Reina Sofía entre 1997 y 2000, durante el periodo en que José Guirao fue director del mismo (1994-2000), confrontando el trabajo de jóvenes creadores españoles (Marina Núñez, Enrique Marty, Ana Laura Aláez, Jorge Galindo, Carmela García, etc.) con el de artistas internacionales de trayectorias ya consolidadas (Gregory Crewdson, Aziz + Cucher, Sarah Jones, etc.). De algún modo, en este espacio y en proyectos como Ofelias y Ulises. En torno al arte contemporáneo español (Bienal de Venecia, 2001) ${ }^{42}$, Doctor consigue dar forma a una heterogénea generación de jóvenes artistas españoles, una suerte de young Spanish artists, que,

42 Este ambicioso proyecto constaba de varios apartados. En primer lugar, la exposición propiamente dicha se articulaba en torno a dos mitos clásicos: Ofelia ("entendida como el mito trágico de la manipulación del entorno") y Ulises ("el que se aventura hacia una empresa difícil soñando el retorno"), con obras de Juan P. Ballester, Ricky Dávila, Álex Francés, Carmela García, Susy Gómez, Valeriano López, Rogelio López Cuenca, Enrique Marty y Marina Núñez. Un segundo bloque de artistas (Carmen Cantón, Alicia Martín, Pedro Mora, Juan Luis Moraza, Javier Velasco) llevó a cabo proyectos de intervención en los espacios del pabellón español. La videocreación española protagoniza el tercer apartado (Jon Mikel Euba, Sergio Prego, Itziar Okariz, Joan Morey, Pepo Salazar, Mapi Rivera, etc.). Por último, completaba el proyecto una exhaustiva revisión de las revistas, libros y catálogos publicados en España sobre arte contemporáneo. R. DOCTOR, «En torno al arte contemporáneo español», en Ofelias y Ulises. En torno al arte contemporáneo español, Madrid, 2001. 
bien situados en circuitos institucionales y galerísticos, marcarán el ritmo del arte español durante la última década del siglo $X X$ y la primera del siglo XXI.

\section{LO RELACIONAL EN EL MUSEO DEL PRESENTE}

Teniendo en cuenta la experiencia de Doctor como gestor de proyectos de nueva creación, el eco mediático que habían acaparado algunos de ellos y su capacidad para promocionar a una generación de jóvenes artistas (una generación cool, moderna, urbana), no debe extrañar que la Junta de Castilla y León le nombrase director del MUSAC. A la vista de los objetivos que esta institución va a marcarse en un horizonte inmediato, es fácil comprender por qué en la programación del MUSAC y en sus estrategias de comunicación pueden encontrarse conexiones con el paradigma relacional gestado en el Palais de Tokyo.

En 2001 el Gobierno regional decide poner en marcha un museo en León sin saber demasiado bien cuál va a ser el plan museológico del mismo, a qué ámbito específico del arte y la cultura va a estar dedicado ni quién se va a encargar de su dirección. Entre 1998 y 2002, en tan solo cinco años, la Comunidad había pasado de no tener ninguna gran equipación dedicada al arte contemporáneo (lo cual no significa que no existiesen espacios de menor "entidad") a tener cinco proyectos funcionando. En 1998 se abre el Museo Esteban Vicente de Segovia; en 2000 se inaugura el Museo Patio Herreriano en Valladolid; en 2002, el CASA (posteriormente, DA2) de Salamanca; y también en 2002, el CAB de Burgos. Cada uno de ellos con un modelo de gestión-financiación y una línea de programación diferente. En ese contexto (y sabemos que, en gran medida, el planteamiento estratégico parte del mismo Doctor), al MUSAC, en su intento por buscar una identidad propia, sólo le quedaba la posibilidad de asentarse sobre el tiempo presente (ya existían dos museos con colecciones de arte moderno, arte del siglo XX), pero presentándose a su vez como un museo (en la Comunidad se habían abierto dos centros de arte actual) en el que la colección ocuparía un lugar privilegiado.

Por otra parte, esa vinculación con lo estrictamente actual respondía a los planes de nuestros responsables políticos, deseosos de diversificar la oferta cultural (y turística) de la Comunidad. Una región rural con un enorme patrimonio histórico (de mantenimiento muy costoso pero hasta cierto punto rentable) que quiere proyectar una imagen de modernidad e innovación. Un museo del presente es, al fin y al cabo, un museo de lo futuro, de lo que está por venir, de lo radicalmente nuevo. Se plantea así un modelo de museo diferenciado de la oferta que existía en la Comunidad y en el conjunto del país (MACBA, MNCARS, CAC Málaga, Guggenheim). En una entrevista Rafael Doctor explicaba: "En primer lugar tengo que partir del hecho de nuestra voluntad de construir un modelo diferente. El objetivo principal es convertirlo en un museo del presente. Puedes observar que se trata de una contradicción de términos. Si es museo no conjuga muy bien con el concepto de presente. Sin embargo nuestro reto se va a basar en jugar en la ambigüedad de esta contradicción" ${ }^{\prime 4}$.

Como estrategia museológica, trabajar sobre el presente significa tener la novedad al alcance de la mano. Existe un riesgo, pero también la seguridad de que lo nuevo, lo joven, lo diferente atraerá al público y de que, por lo tanto, el riesgo del sondeo legitimará el gesto de exploración y descubrimiento. No obstante, desde el MUSAC en ningún momento se ha conseguido articular una reflexión fuerte, un discurso sólido

43 J. HERNANDO, «Entrevista con Rafael Doctor Roncero», Cimal no 56, 2003, p. 17. 
sobre el presente, sobre los problemas relacionados con el arte del presente (en España o a nivel internacional) o con la posibilidad de museizar (e historiar) esas prácticas. El interés por el presente, por lo nuevo, ha sido más bien una estrategia promocional, mediática. En este sentido, a Bourriaud hay que reconocerle la capacidad para armar un discurso que, pese a las críticas recibidas, ha conseguido captar algunas de las dinámicas artísticas actuales y que, además, ha resultado ser tremendamente influyente.

El presente es, a su vez, algo característico de lo relacional. Como hemos visto, las prácticas relacionales se conjugan siempre en presente $\mathrm{y}$, de hecho, se les critica por su ahistoricidad, por el olvido consciente de sus antecedentes, de aquello que las podría hacer (o no) pertinentes en un tiempo determinado. Algo similar pasa con nuestra movida, amnésica y olvidadiza, afectada por una especie de complejo de Peter Pan y empeñada en vivir siempre en un presente esquizofrénico. En este y en otros puntos, confluyen de nuevo nuestra tradición relacional y el "paradigma Bourriaud". Por una parte, tenemos lo festivo, superficial, desintelectualizado, megalómano, acomplejadamente internacional, de la cultura española (desde los años ochenta hasta la actualidad), ahora en un mapa institucional hiperdesarrollado en el que es necesario buscar nuevos modelos de legitimación en el presente. $Y$, por otra, encontramos en el MUSAC una serie de elementos que conectan con el discurso relacional que se irradia desde el Palais de Tokyo (he ahí el modelo legitimador). De nuevo, no me atrevería a señalar una influencia directa, pero desde luego hay aspectos de la programación y otros muchos de la "estrategia de comunicación" y de la imagen corporativa (que no entraremos aquí a valorar) que nos hacen pensar en un alineamiento estratégico con las propuestas de Bourriaud: las individuales de Huyghe ( $A$ Time Score, 2007) y González Forester (Noc- turama, 2008), la aclamada proyección de la película Zidane. Un retrato del siglo XXI (2006) de Douglas Gordon y Philippe Parreno, la presencia de las instalaciones de Tiravanija o Alicia Framis (artista que ha conseguido autoinscribirse en el paradigma relacional) en la colectiva Fusión. Aspectos de la cultura asiática en la colección del MUSAC (2005) o el carácter relacional de exposiciones como las de Dora García (Vibraciones, 2005), Enrique Marty (La caseta del alemán, 2005), Pipilotti Rist (Problemas buenos, 2005) o Globos Sonda $(2006)^{44}$.

Como apuntaba más arriba, lo relacional es un fenómeno institucional, aunque, como paradigma (y aquí lo relacional nos tiende una trampa de la que no es fácil salir), resulta difícil tratar los elementos que en él se integran (discurso teórico, modelos institucionales, prácticas curatoriales y trabajos artísticos) de manera independiente. Estos elementos se retroalimentan hasta casi confundirse. Soy consciente del peligro que conlleva identificar la obra de un artista con un modelo de gestión, por más que su trabajo pueda quedar connotado o inscrito en un discurso curatorial. Hemos vinculado la obra de Aláez con una tradición relacional, un trabajo artístico que dialoga con una determinada dinámica cultural (la movida de los ochenta y la posterior resaca de los noventa) dándole cierta continuidad. En el caso del MUSAC, parece imposible acercarse a la obra de Pierre Huyghe, Dominique González Forester, Douglas Gordon, Philippe Parreno o Tiravanija obviando que son piezas claves en el desarrollo de las teorías y programas expositivos de Bou-

\footnotetext{
44 A. MARTíN, «Reinventar la modernidad. Globos Sonda / Trial Balloons», Babelia, 12 de agosto de 2006, p. 13: "Aunque los comisarios plantean esta exposición como una suma de subjetividades sin un soporte discursivo explícito, no es difícil percibir en el guión del proyecto un fuerte eco de los postulados de Nicolas Bourriaud, tanto de su Estética Relacional como, sobre todo, de su Postproducción".
} 
rriaud. Del mismo modo, resulta inevitable vincular el trabajo de Alaska ${ }^{45}$ con la movida madrileña de la que ha sido su principal icono. Es decir, tenemos un conjunto de trabajos que aparecen vinculados a determinados modos de entender y promocionar el arte y que, por eso mismo, se convierten en símbolos cuya puesta en juego no puede considerarse en absoluto casual.

Dicho esto, el acercamiento a (o el alineamiento con) lo relacional parece una opción muy inteligente si tenemos en cuenta la necesidad institucional de encontrar un modelo diferenciado del resto de los existentes en el contexto español y el éxito (el esplendor) que el Palais de Tokyo había cosechado en el cumplimiento de los objetivos señalados. Los objetivos del MUSAC son, en principio, bastante parecidos: promocionar del arte español (y castellanoleonés) a nivel internacional ${ }^{46}$, proyectar una imagen de modernidad dentro y fuera

\section{-}

${ }^{45}$ En 2004, el MUSAC colaboró en la producción del disco de Fangoria Arquitectura efimera. En su web, se puede leer (http://musac.es/index.php?secc= 5\&subsecc $=0$ ): "La Consejería de Cultura y Turismo, a través del MUSAC, ha colaborado en el nuevo disco del grupo FANGORIA, editado por DRO East West, bajo el título Arquitectura Efímera. El proyecto consiste en un DVD que contiene seis vídeos concebidos y dirigidos por seis artistas: Carles Congost, Manu Arregui, Ruth Gómez, Christian Jankowski, Marina Núñez y Martín Sastre. A través de su trabajo, los artistas recogen las posibilidades de la arquitectura efimera que proponen las seis canciones de Fangoria".

${ }^{46}$ R. Doctor, «Volumen 1», en Musac. Colección, Vol 1., León, 2005, p. 13: "El hecho de contrastar el arte español con el internacional es una de las tareas más urgentes que aquí nos requerimos. (...) España, pese a haberse consolidado como un país avanzado en Occidente, no ha sido capaz hasta la fecha de imponer su producción artística en el complejo engranaje de lo internacional. El incipiente mercado artístico autóctono junto al incremento de instituciones artísticas locales, regionales o nacionales, ha posibilitado una supervivencia del sistema pero no ha conseguido, salvo raras excepciones, expandirse más allá de su propio territorio. La mayor parte de nuestros artistas son auténticos desconocidos en foros exteriores y su presencia cada vez parece disminuir más". de la Comunidad ${ }^{47}$, conseguir un importante eco mediático (marca MUSAC) y unas elevadas cifras de visitantes que potenciasen el turismo ${ }^{48}$ y revitalizasen el urbanismo leonés (es de sobra conocido el efecto Guggenheim en Bilbao). Sin embargo, el contexto en el que se pone en marcha el MUSAC es muy diferente. Y aquí es donde aparecen serios problemas (lo ruinoso del paradigma).

La implantación de un gran museo de marcado carácter internacional ${ }^{49}$ en un

${ }^{47}$ S. CLEMENTE, «Presentación», en MUSAC. Colección. Vol. 1, Op. cit.: “Conscientes del interés que despierta la creación contemporánea en la sociedad, la Junta de Castilla y León pone en marcha el Museo de Arte Contemporáneo de Castilla y León (MUSAC) con el objetivo de dar a conocer en nuestra Comunidad el arte más contemporáneo y actual, y proyectar un nuevo concepto de cultura en relación con las artes plásticas".

${ }^{48}$ V. VIÑAS, «La apertura del MUSAC ha disparado un $12 \%$ los turistas que visitan León", Diario de León, 21 de abril de 2006: "Más de 180.000 personas han visto alguna de las exposiciones de este centro, que abrió sus puertas en abril del año pasado. La consejera de Cultura de la Junta, Silvia Clemente, afirmó ayer que mientras el turismo había crecido de media un 5,4\% en la comunidad, en León el incremento se disparaba casi cinco puntos por encima de las otras ocho provincias". En sus cinco años de vida, el MUSAC ha alcanzado la cifra de 744.000 visitantes.

49 http://musac.es/index.php? secc $=1$ \&subsecc $=1$ : "El objetivo de este museo es convertirse en una pieza fundamental en el desarrollo del Arte Contemporáneo, a nivel internacional. Este museo nace con un amplio sentido experimental a la hora de concebir y desarrollar proyectos $y$ exposiciones a todos los niveles. El MUSAC se encuentra trabajando exclusivamente en el área temporal del presente, marcado por la memoria más cercana: el museo se inicia con la idea de desarrollar un nuevo comportamiento a la hora de abordar el arte del siglo XXI. Los años finales del siglo pasado supondrán el inicio del parámetro temporal del que partir. De esta forma, el MUSAC aparece como un claro exponente de una nueva etapa cultural, donde ya aparecen asentados valores estéticos y comportamientos artísticos que en un momento pasado fueron revolucionarios. Como $\mathrm{Mu}$ seo del Presente o Museo del Siglo XXI, el MUSAC asumirá la responsabilidad de proyectarse sobre un terreno, que como todo experimento, conlleva un amplio carácter de riesgo. El museo se construye con el propósito de ser un lugar interrelacional donde el público deje de ser un mero 
contexto como el leonés (o castellanoleonés) produjo un fuerte descontento en el precario tejido cultural ya existente, al que la institución considera provinciano, caduco, desfasado, poco moderno, y que, sin embargo, en muchos casos, está compuesto por una red de gestores y creadores muy comprometidos que con mucho esfuerzo tratan de generar una estructura horizontal de espacios e iniciativas artísticas. Tarea en la que casi siempre topaban con un sinfín de problemas de tipo político y presupuestario que, por supuesto, no se le presentan a la institución. El museo, hasta ahora, ha dado la espalda a esa débil estructura y los intentos por integrarse de una manera respetuosa y constructiva en ella han sido demasiado torpes y tardíos. Ante las críticas, siempre se esgrime el mismo argumento: la educación y mediación artística como justificación de programaciones y estrategias de comunicación y como principal medio de arraigo en el contexto local. Si en algún momento la exposición (o si quiera el museo) se convierte en un espacio relacional en el que se posibilita el establecimiento de vínculos sociales es gracias al encomiable trabajo del DEAC (Departamento de Educación y Acción Cultural) y de la Biblioteca-Centro de documentación, y rara vez por las sinergias que pueda generar una exposición. En cambio (y este problema no es ni mucho menos privativo del MUSAC), el trabajo de mediación (salvo por las visitas guiadas que aseguran un flujo constante de público) parece relegado a un segundo lugar, demasiadas veces carente de reconocimiento y financiación. De manera inevitable, los recursos destinados a una actividad son proporcionales a la visibilidad que esta suministra al museo. Como en lo relacional, el trabajo didáctico, la creación de espacios de trabajo, la articulación de discursos críticos, acaba siendo un simple medio de legi-

elemento pasivo que contempla". timación de la gran máquina institucional productora de un capital mediático, simbólico y económico ${ }^{50}$.

Con respecto al calado socio-político de la programación expositiva, y aunque pudiera parecer que el MUSAC aboga por una línea festiva y despolitizada, en la colectiva inaugural Emergencias (2005) ${ }^{51}$ se apuntaban unos objetivos políticos y sociales muy concretos: "la necesidad actual de un museo es crear un compromiso político social a través de distintos proyectos generando una conciencia colectiva que, aunque utópica, reflexione sobre nuestro presente". Desde estos presupuestos, parece fácil solidarizarse con las miserias del continente africano, y sin embargo, resulta casi imposible (no es rentable) participar de los problemas de las comunidades ("generar una conciencia colectiva") en las que se asienta el museo (de nuevo el DEAC o trabajos puntuales como Canal Gitano de Antoni Abad pueden servir como excepciones que confirman la regla) porque simplemente se reduciría el número de visitantes e impactos en prensa $\mathrm{y}$, con ellos, el rédito político

\section{-}

${ }^{50}$ V. DEL RíO, «La educación artística ante el fraude del conocimiento», en Estrategias críticas para una práctica educativa en el arte contemporáneo, Valladolid, 2007.

51 http://www.musac.es/index.php?ref=10000: "Como reflejo de una realidad presente, el arte contemporáneo intenta hacer hincapié sobre esa realidad circundante. Por esto, la necesidad actual de un museo es crear un compromiso político social a través de distintos proyectos generando una conciencia colectiva que, aunque utópica, reflexione sobre nuestro presente. / (...) Con esta exposición se pretende crear conciencia en el espectador de las necesidades acuciantes de nuestro mundo. De este modo y de manera activa se plantean cuestiones abiertas que quizá obviamos, imbuidos por la sociedad del bienestar, donde a través de lo mediático somos incapaces de discernir entre una imagen que muestra el hambre en África y un anuncio de perfume. Siendo en este punto donde se pierde la delgada línea que separa lo que supuestamente es el primer y tercer mundo. (...) Emergencias, por tanto, se plantea desde una perspectiva utópica y esperanzadora, partiendo de un planteamiento radicalmente comprometido y diferente a la hora de mostrar una colección". 
del proyecto. De este modo, la institución da cauce a una politicidad light, ya desactivada, desempeñando una función compensatoria. Los discursos autocríticos son neutralizados y el campo de lo político se delimita una vez más "desde arriba" (lo político financiado desde la política), lo cual deja fuera de juego cualquier tipo de discurso disidente con respecto a cómo se gestionan los recursos públicos destinados a la creación contemporánea ${ }^{52}$.

A ello contribuye la tendencia a la espectacularización y bienalización del hecho artístico que subyace a las líneas de actuación del museo. La primera publicación editada por el MUSAC a modo de presentación pública en ARCO, Files $(2004)^{53}$, adelanta algunas de las constantes que van a marcar el rumbo de la institución. El libro (con más de 600 páginas) es un proyecto curatorial de Octavio Zaya, que a su vez invita a treinta y cinco comisarios a realizar una selección de artistas representativos del panorama actual. Files es, por tanto, un comisariado de comisarios. Y, al mismo tiempo, un libro visual en el que las prácticas y discursos artísticos, en la inmensa mayoría de los casos, se ven reducidos a su foto, a una imagen descontextualizada de la que no se nos da ninguna información. El arte se consume de un vistazo, se ve, se siente; el arte está ahí, para nosotros, porque un comisario elige a varios artistas que considera representativos

${ }^{52}$ D. CORBEIRA, «Arte político en los 90. Una posibilidad», Papers d'art nº 75, 1998, p. 33.

${ }^{53}$ R. DOCTOR, «Files en MUSAC», en Files, León, 2004, p. 1. Comisariado por Octavio Zaya, Files es "un libro visual que ha sido distribuido gratuitamente en ARCO 04, cuyo contenido recoge las pautas necesarias para la creación de la Colección Ideal del siglo XXI. Para ello han sido invitados a participar 35 comisarios nacionales e internacionales de reconocido prestigio dentro del mundo del Arte Contemporáneo. El objetivo del proyecto es potenciar la presencia del MUSAC sin necesidad de mantener un espacio físico en dicha feria". de una realidad dada; $y$, lo más importante, el arte no necesita ser explicado, criticado, teorizado o problematizado ni por el comisario ni por el creador, basta el gesto de selección para que el trabajo quede legitimado como parte de "una colección ideal del siglo XXI".

La importancia desmedida concedida al comisario es una de las características fundamentales de los procesos de bienalización $^{54}$ de los que el MUSAC participa en varios sentidos. Sin ir más lejos, en la presentación del catálogo Globos Sonda, Rafa Doctor explicaba: "En estos momentos, desde dentro estamos estudiando la posibilidad de repetir la experiencia cada dos años y de esta forma, convertir Globos Sonda en una verdadera bienal realizada en el seno de una institución museística. Todos los parámetros que ahora mismo manejamos nos indican que es necesario y que sin duda el proyecto que aquí nace será una de las principales señas de identidad del MUSAC"55. Globos Sonda, cuyo título inicial era Acta del Presente, ha sido una de las exposiciones más criticadas del MUSAC por su espectacularidad, excesos presupuestarios, ausencia de discurso vertebrador $\mathrm{y}$ desmedida obsesión por la novedad de las creaciones ${ }^{56}$. Y, precisamente por eso, el centro llega a plantearse convertirla en "seña de identidad", en una cita periódica que potenciase aún mas su imagen internacional y su capacidad para marcar el ritmo de lo nuevo, de aquello que puede o no entrar

-

54 D. CORBEIRA, «La bienalización del arte contemporáneo», Brumaria nº 2, 2002; G. PICAZO, «El inicio de la bienalizacion: arte e instrumentalización», en Impasse 5. La década equívoca: el trasfondo del arte contemporáneo español en los 90, Op. cit.

55 R. DOCTOR, «Globos Sonda (I)», en Globos Sonda, León, 2006.

56 A. MARTín, «Reinventar la modernidad. Globos Sonda / Trial Balloons», Art. cit.; F. CASTRO FLÓREZ "Globos Sonda, Calma chicha», $A B C D, 13$ de mayo de 2006; M. NAVARRO, «Supervivencia de la sensibilidad», El Cultural, 18 de mayo de 2006. 
en el museo del siglo XXI. Como señala Catherine Francblin, "la apertura de una bienal es en primer lugar la señal de una voluntad política y el signo de un viraje socio-económico decisivo" ${ }^{57}$. La idea de crear una bienal dentro de una institución como el MUSAC, cuando esta sólo tenía un año de vida, apunta de nuevo hacia un tipo de políticas culturales poco racionales e insostenibles a medio plazo en las que los comisarios, auténticos protagonistas del actual panorama mediático, se limitan a justificar una selección heterogénea y supuestamente representativa del momento presente. Selección que, en el fondo, acaba deglutiendo los trabajos artísticos, más o menos relacionales, que se pretenden dar a conocer.

En relación con estas cuestiones me gustaría concluir con una extensa cita de Jorge Luis Marzo, una de las voces críticas más lúcidas de este país, que, además de señalar con meridiana claridad algunos de los problemas que aquí hemos tratado de abordar, consigue lanzar una propuesta con respecto a cuál puede o debe ser el papel del comisario en un momento en que el sistema gira en torno a su figura:

"Hoy la política cultural está al servicio de la compleja trama turística que existe en España. Se inauguran bienales de arte o se abren decenas de museos de arte contemporáneo en otras tantas ciudades, con presupuestos que hipotecan casi completamente la financiación de cualquier otro proyecto cultural en la ciudad o la región (los casos de Artium en Vitoria, el MUSAC en León, o el CAC en Málaga son recientes espejos). Esos museos no están allí para generar estructuras locales de creación, sino para convertirse en iconos de la ciudad gracias a sus arquitecturas; para acabar albergando determinadas colecciones de artistas

57 C. FraCnBLIN, «À quoi servent les biennales d'art», Beaux Arts Magazine no 181, 1999, p. 84. famosos o para acoger exposiciones de corte internacional, altamente espectacularizadas $y$ facilmente mediatizables en las rutas turísticas. / (..) El comisario crítico debe, ante todo, dejar de pensar en corrientes estéticas y en adivinar cuáles de ellas tienen cabida institucional, y debería centrarse en ayudar a que las prácticas y usos creativos de muchos sectores de la sociedad (incluyendo los no estrictamente artísticos) puedan desplegar su potencial; debe favorecer la comprensión de esta situación entre los responsables institucionales; debe implicarse directamente en la defensa de los derechos laborales y representacionales de los artistas, creadores, colectivos y asociaciones; debe buscar nuevas fórmulas de financiación que conduzcan a una desinstitucionalización de los costes para que estos reviertan definitivamente en los actores productivos; debe desinstitucionalizar el contexto museístico en el que habitualmente acaban secuestradas muchas experiencias creativas; debe favorecer el experimento pero en directa relación con la experiencia existente que ha dado lugar al experimento; debe deshacer, y en profundidad, la perniciosa mentalidad formalista en la realización de exposiciones, potenciando la producción horizontal e investigadora de la muestra. El comisario crítico debe aprovechar mucho más la creación de redes (Internet) por encima del fetiche del catálogo, cuya única utilidad, a menudo, es la propaganda institucional y la justificación promocional de la misma. Un comisariado libre debe dejar de pensar que no puede morder la mano que le da de comer; por muchas razones, pero la más importante es que esa mano no es la de la institución sino la del artista. Un comisario consciente de la situación política de las artes (de su uso y de su abuso) debe tener presente que el $92 \%$ de la gente (que es el porcentaje de personas que nunca va a museos) no puede estar enteramente equivoca$d a^{\prime \prime 5}$.

-

58 J. L. MARZO, «El comisario frente a la desaparición de la política cultural», http://www.plataforma curatorial.es/category/uncategorized 